\title{
METACOGNIÇÃO E SUCESSO ESCOLAR: ARTICULANDO TEORIA E PRÁTICA
}

\author{
CLAUDIA DAVIS \\ Programa de Estudos Pós-Graduados em Psicologia da Educação, \\ da Pontifícia Universidade Católica de São Paulo e Departamento \\ de Pesquisas Educacionais, da Fundação Carlos Chagas \\ cdavis@fcc.org.br
}

MARINA M. R. NUNES

Departamento de Pesquisas Educacionais, da Fundação Carlos Chagas e Colégio Santa Cruz mnunes@fcc.org.br

\section{CESAR A. A. NUNES}

Escola do Futuro, da Universidade de São Paulo e Núcleo de Tecnologia da Informação e Comunicação Aplicadas à Educação, da Universidade Anhembi-Morumbi cnunes@futuro.usp.br

\section{RESUMO}

Este artigo busca salientar a importância da metacognição para os processos de aprendizagem e para o sucesso escolar. Para tanto, discute a necessidade de se construir, nas salas de aula, uma cultura do pensar, que propicie aos alunos: a. uma forma de explicitar, desde cedo, modalidades de pensamento, tornando-as, assim, passiveis de ser compartilhadas; b. um estímulo ou motivação para pensar, de forma a alcançar decisões acertadas; c. a coragem para enfrentar situações novas; $d$. a transferência de estratégias e conhecimentos gerados em um dado contexto para outros. Um aspecto central na implementação de uma cultura do pensamento é desenvolver habilidades metacognitivas, pois é por meio delas que se torna possível a elaboração de conhecimentos e formas de pensar que assegurem maior possibilidade de sucesso e generalização, bem como a aquisição da autonomia na gestão da aprendizagem e na construção de uma auto-imagem de aprendiz competente. Exemplos de

Trabalho encomendado pelo GT de Psicologia da Educação e apresentado na $27^{\mathrm{a}}$ Reunião da Associação Nacional de Pós-Graduação e Pesquisa em Educação - ANPEd -, em Caxambu, de 21 a 24 de novembro de 2004. 
como implementar essa proposta são fornecidos, destacando como a organização do ensino torna os alunos sujeitos de sua própria aprendizagem.

PROCESSO ENSINO-APRENDIZAGEM - DESENVOLVIMENTO COGNITIVO METACOGNIÇÃO - AUTO-IMAGEM

\section{ABSTRACT}

METACOGNITION AND SUCCESSFUL LEARNING: ARTICULATING THEORY AND PRACTICE. This article aims to stress the importance of metacognition for learning processes and for reaching success in school. The discussion centres on the importance of building a "thinking culture" in all classrooms, making possible to the students to: a. explicit their modalities of thinking, allowing them to be shared; b. be motivate to think in order to reach adequate decisions; $c$. face new situations; $d$. transfer both strategies and knowledge acquired in one context to another. A central point in the implementation of such culture is to develop metacognitive abilities, since this seems to be an effective way of learning not only what to learn but also how to learn. This acquisition, in turn, furnishes a greater possibility of becoming an autonomous learner, what implies the construction of a positive self-image as student. Examples of how to do this in school are given, pointing out the manner through which teaching organization permits students to master their own learning process.

LEARNING PROCESSES - COGNITIVE DEVELOPMENT - METACOGNITION - SELF CONCEPT

Pode parecer fortuito iniciar um artigo sobre metacognição e aprendizagem escolar, retomando um conceito já por demais sabido: o papel da escola. De fato, é possível que o leitor imediatamente diga a si mesmo: "Ora, o papel da escola é construir um cidadão lúcido, crítico e autônomo!", sentindose desmotivado para seguir adiante no texto. No entanto, nossa experiência mostra que, quando nos inquirimos acerca de como fazer para preparar esse cidadão, segue-se um imenso silêncio. E não porque não se saiba a resposta, mas, porque ela parece, de certa forma, óbvia. Insistindo mais um pouco, é possível que encontremos respostas do tipo: "compete à escola ensinar a ler, escrever, entender noções básicas do mundo físico e social, solucionar problemas e assim por diante". Essas respostas, no entanto, não nos parecem satisfatórias e voltamos a perguntar: "mas como a escola faz isso"? E novamente não encontramos respostas.

Parece, então, ser conveniente salientar que cabe à escola, sim, formar o cidadão, entendido como aquele que participa plenamente da sociedade, tomando decisões acertadas em função de um projeto pessoal que se articula a um projeto social mais amplo. Nesses termos, a tarefa da escola torna-se mais 
Metacognição e sucesso escolar...

complexa do que meramente transmitir informações ou ensinar habilidades. Efetivamente, ainda que essas sejam qualidades importantes a ser desenvolvidas, não explicitam como a escola deve agir para atingir seus fins. Tal como vemos, para encurtar uma longa história, o cidadão capaz de tomar decisões adequadas precisa dispor de: informações pertinentes a respeito do meio físico e social, de si mesmo e dos outros; estratégias de pensamento que lhe permitam operar sobre essas informações; valores que orientem a sua ação.

Dependendo de como a escola valoriza essas três tarefas, diferentes culturas escolares são construídas. Quando o aluno entra na escola - e se ela cumprir sua função - ele passa por um processo de enculturação que o fará sair dessa instituição diferente de como entrou. Mas o que se entende por enculturar? Ora, enculturar refere-se ao processo de apropriação de uma cultura, que se dá por meio de exposição a modelos aceitos (via imitação), explicações, interações e feedbacks que forneçam informações úteis para a aprendizagem em curso (Tishman, Perkins, Jay, 1999; Bruner, 2001).

A experiência mostra que é muito mais fácil identificar culturas voltadas para a informação (que buscam levar o aluno a aumentar e aprimorar conhecimentos, como, por exemplo, a das chamadas escolas conteudistas) e aquelas que dão ênfase à formação dos alunos, ensinando-lhes, notadamente, valores e atitudes considerados positivos na orientação da conduta. Fazendo uma caricatura da situação, pode-se dizer, no primeiro caso, que o resultado da ação escolar será um aluno bem informado mas que, não necessariamente, sabe como empregar seus conhecimentos para tomar decisões acertadas em seu tempo e sociedade. No segundo, tem-se sujeitos que sabem, "acertadamente", a direção a ser tomada, faltando-lhes, no entanto, uma base conceitual sólida que lhes permita articular informações que orientem sua ação.

Escolas que priorizam e sabem como estimular e promover o raciocínio dos alunos - fazendo uso do pensamento para processar informações e orientar a tomada de decisões acertadas de acordo com valores consensualmente priorizados em seu tempo e sociedade - são muito mais raras. E o são porque promovem a cultura do pensar, que permite àqueles que a freqüentam tirar maior proveito da experiência escolar: aprendem a controlar melhor a impulsividade; aumentam sua capacidade de reflexão e planejamento; analisam e fundamentam a escolha feita, entre as opções disponíveis. Daí a necessidade de se entender melhor o que vem a ser uma "cultura do pensamento" (Tishman, Perkins, Jay, 1999, p.5). 


\section{INVESTINDO NA CULTURA DO PENSAMENTO}

Pensar é a atividade humana mais complexa. Ela envolve o emprego de símbolos e signos para representar aspectos do ambiente físico e social, permitindo-nos ir além da apreensão perceptual. Pensar leva à formação de conceitos abstratos tais como "igualdade, liberdade e fraternidade", que podem, como freqüentemente é o caso, nem mesmo ter um referente concreto. Podese concluir, portanto, que pensar liberta a ação humana das restrições de seu ambiente imediato (Zimbardo, Ruch, 1977). Pensar envolve habilidades cognitivas tais como percepção, atenção, simbolização, seleção, memória, transferência, avaliação etc., cujo produto chamamos pensamento. Os pensamentos, por sua vez, são de diferentes tipos e, para fins didáticos, facilita compreendê-los como dispostos em um continuum que vai desde o pensamento realista, que corresponde às características e exigências de uma situação externa, até o pensamento criativo, ou seja, o que vai além do aparente e do imediato para chegar a uma nova forma de conceber velhos problemas. Imaginar, fantasiar, devanear podem ser considerados tipos de pensamento. Quando a atividade mental se volta para a resolução de problemas, dizemos que o pensamento assume a forma de raciocínio: um processo pelo qual se procura chegar a conclusões a partir de princípios e evidências, inferindo, com base no conhecido, novas possibilidades ou avaliando os resultados obtidos.

Dentre as diferentes formas de raciocinar, destacam-se a dedutiva e a indutiva. A primeira envolve proceder do geral para o particular, empregando proposições amplas para entender, explicar, avaliar e/ou monitorar eventos específicos. A dedução é bastante utilizada, em especial por ser mais rápida e, por vezes, mais eficiente, do que a indução. A representação gráfica, por exemplo, é uma forma de raciocínio dedutivo que permite ativar o conhecimento prévio e abrir espaço para novas idéias. Para pensar dedutivamente é preciso preencher noções gerais com informações precisas, de modo a elaborar novos conceitos, a formular previsões e a delinear planos ou procedimentos para resolver problemas. Aprender a pensar dedutivamente coloca os indivíduos em posição de controlar os eventos de sua própria experiência.

Já o raciocínio indutivo refere-se ao processo pelo qual conexões entre fatos são estabelecidas, possibilitando generalizações a partir delas. A articulação dos fatos é importante para criar novas idéias, levantar novas hipóteses e propor novas teorias a serem testadas. $\bigcirc$ contexto da sala de aula permite, 
Metacognição e sucesso escolar...

quando necessário, acionar "a tecla pause ou o slow motion", de modo a alterar o tempo dos eventos em estudo. Essa lentidão ou parada proposital permite a identificação dos fatores centrais do objeto de estudo e a realização de inferências indutivas, ou seja, de generalizações.

Em suma, o raciocínio indutivo é o processo de construir idéias a partir da experiência. Já o dedutivo refere-se ao processo de aplicar idéias gerais ou conceitos a problemas específicos na experiência. Raciocínio indutivo envolve alocar significados por meio da busca deliberada dos fatos da experiência, sua categorização e construção teórica. $\bigcirc$ pensamento dedutivo, por sua vez, requer a aplicação de idéias gerais à experiência particular, envolvendo previsões, planejamento e solução de problemas. Fica claro, portanto, que a aprendizagem depende, em grande parte, tanto dos processos de pensamento dedutivos como indutivos, de tal forma que experiências apóiam o desenvolvimento de idéias, as quais serão, futuramente, testadas e mais bem desenvolvidas. Indução e dedução constituem, assim, modos de pensar de primeira importância (Clarke, 1990).

O problema da escola é que se tende a supor, nela, que os alunos já são capazes de operar cognitivamente e, notadamente, de realizar raciocínios dedutivos e indutivos. Com isso, os professores se sentem liberados da tarefa de ensinar a pensar, preocupando-se, quase que exclusivamente, em veicular e ensinar informações e valores. Claro que se aprende a pensar em muitos e diversificados lugares, mas só a escola pode fazê-lo de forma intencional e sistemática. Para instalar, então, uma cultura do pensamento, é importante que os alunos, em interação com seus professores e pares:

- Sintam-se estimulados a usar o pensamento para resolver problemas, ou seja, estejam motivados, de um lado, a tomar decisões acertadas, percebendo que isso requer constante análise entre os fins pretendidos e os resultados encontrados, de tal modo que o pensamento alimente a ação e vice-versa, refinando-se mutuamente; de outro, que valorizem esse processo, dando-se conta de que é por seu intermédio que se chega a decisões que ocasionam o impacto desejado em si mesmo e/ou no meio físico e social. Motivação caracteriza-se por uma situação plena de energia, que leva a um esforço para atingir um determinado objetivo, por intermédio de seleção atenta dos dados relevantes e organização de uma seqüência integra- 
da de estratégias de ação, persistindo na atividade até que as metas iniciais sejam atingidas.

- Selecionem e empreguem, de forma deliberada, no cotidiano da sala de aula, um vocabulário capaz de nomear e reapresentar modalidades de pensamento, permitindo alcançar aquelas de nível mais elevado. Cabe, nesse caso, empregar palavras e conceitos que possibilitem não apenas um uso mais preciso, como também uma explicação mais acurada acerca do que se passa durante a atividade intelectual. Palavras tais como "conclusão", "hipóteses", "teorias", "evidências" constituem bons exemplos. Assim, se o aluno diz: - "Eu acho isso a respeito daquilo", o professor deve responder, por exemplo: - "Interessante essa sua teoria", indicando que o aluno pode representar seu pensamento, ou a forma pela qual articulou diferentes idéias, com maior precisão. $\bigcirc$ objetivo é evitar palavras excessivamente vagas, como "achar", "acreditar", "sentir", "encontrar", substituindo-as por: "a minha hipótese é...", "a minha conclusão é...", "investigando o assunto...", "esta idéia foi confirmada pelas seguintes evidências...", "eu interpreto estes dados...", "este fato implica...", "essa noção não se confirmou por...", e assim por diante. Habituados a esse vocabulário do pensar (Tishman, Perkins, Jay, 1999), torna-se mais fácil para os alunos compartilhar tanto seu pensamento como as estratégias que selecionaram para resolver um determinado problema. Um vocabulário comum permite discutir esses aspectos com colegas e professores, sem a ambigüidade que costuma marcar a linguagem cotidiana.

- Enfrentem situações novas e inesperadas, mediante a identificação das variáveis críticas que, ao permitir que a tarefa se configure mentalmente, levem à elaboração de estratégias flexíveis de pensamento e ao monitoramento constante da forma pela qual são empregadas.

- Transfiram, articuladamente, as estratégias de pensamento utilizadas em um dado contexto, bem como os conhecimentos gerados a partir delas, para outros. A transferência é a base da acumulação do conhecimento e da aprendizagem humana, marcando em especial a possibilidade de, partindo do conhecido (conteúdos, estratégias, habilidades etc.), articulá-lo de outra forma, chegando a novas soluções, conclusões e idéias. Um ensino voltado à transferência busca ajudar os alunos a entender como algo se vincula a outro, como algo 
Metacognição e sucesso escolar...

pode ser compreendido em termos de outro. Assim, trabalhar com analogias, percebendo o atributo comum entre dois termos, antecipar diferentes contextos em que se pode aplicar um mesmo dado, reconhecer na experiência cotidiana um conteúdo escolar significa não esperar que a transferência apareça espontaneamente, ativando o aprendizado armazenado na memória em circunstâncias pertinentes. É a transferência que possibilita estender habilidades e posturas deliberadamente para outros cenários, ajudando os alunos a pensar sobre suas idéias, articulando-as com as veiculadas em outras disciplinas e aplicando-as a contextos escolares e não escolares.

Investir nessa cultura do pensamento significa tentar ampliar e aprimorar as possibilidades de sucesso, levando os alunos a conquistar aprendizagens mais profundas e duradouras. Inúmeros estudos (Goodrich, 1996, Dolly, 1999) apontam a necessidade de articular a escola da informação com a escola da formação e, talvez, isso possa ser mais bem feito, incentivando a metacognição (Grangeat, 1999). Esse conceito permite conciliar a escola preocupada com a construção de conhecimentos e aquela zelosa dos valores humanos universais.

\section{DESTRINÇANDO UM CONCEITO COMPLEXO: A METACOGNIÇÃO}

Metacognição é um conceito ainda hoje em discussão. Cunhado por Flavell ele se refere à "cognição sobre a cognição", entendendo-se por "cognição" mais o processo de conhecimento do que os conhecimentos resultantes desse processo. Pode-se, assim, dizer que metacognição é a atividade mental por meio da qual outros processos mentais se tornam alvo de reflexão: "Metacognição refere-se ao conhecimento que se tem sobre os próprios processos cognitivos, e produtos ou qualquer coisa relacionada a eles, isto é, o aprendizado das propriedades relevantes da informação ou dos dados". Ou ainda (e na mesma página), "metacognição refere-se, entre outras coisas, ao monitoramento ativo e à conseqüente regulação e orquestração desses processos em relação aos objetos cognitivos ou dados sobre os quais eles incidem, usualmente a serviço de alguma meta ou objetivo concreto (Flavell, I976, p.232, tradução nossa).

Fica claro, portanto, que, ao fazer uso da metacognição, o sujeito torna-se um espectador de seus próprios modos de pensar e das estratégias que 
emprega para resolver problemas, buscando identificar como aprimorá-los. Nesse sentido, e tal como postula Flavell (1976), metacognição envolve também monitoramento ativo dos processos de pensamento, regulando-os e orquestrando-os para alcançar um determinado objetivo. Esse autor aponta dois componentes centrais nesse conceito: os conhecimentos metacognitivos e as experiências metacognitivas.

- Conhecimentos metacognitivos dizem respeito: ao produto cognitivo, ou seja, ao conhecimento de que determinados conceitos, práticas e habilidades já são dominados, enquanto outros ainda não o foram, reconhecendo o que se é (ou não) capaz de alcançar; à compreensão dos processos cognitivos, ou seja, da maneira pela qual o pensamento e as funções superiores - atenção, memória, raciocínio, compreensão - atuam na resolução de um problema.

- Experiências metacognitivas designam: os processos pelos quais se é capaz de exercer controle e auto-regulação durante a tarefa de resolução de um problema, permitindo ao sujeito tomar consciência do desenrolar da sua própria atividade.

Assim, gerir uma tarefa é poder guiá-la, avaliá-la, corrigi-la e regulá-la, caminhando em direção ao pretendido. Mas não só isso. A gestão da atividade deve permitir a compreensão e a explicitação das relações entre os procedimentos, o objetivo e o desempenho obtido. Quando se consegue isso, é possível alcançar um nível mais abstrato e explicativo de compreensão da situação-problema, formulado-a em termos generalizáveis e, portanto, transferíveis.

Fica patente, então, que a metacognição é aspecto central na implementação de uma cultura do pensamento, uma vez que é por seu intermédio que se pode: construir conhecimentos e habilidades que tenham maior possibilidade de sucesso e de transferência; aprender estratégias de solução de problemas que sejam passíveis de serem auto-reguladas; adquirir autonomia na gestão das tarefas e nas aprendizagens, auto-regulando-se e se auto-ajudando; construir uma auto-imagem de aprendiz produtivo e, com isso, obter motivação para aprender. 
Metacognição e sucesso escolar...

\section{ENFRENTANDO E SOLUCIONANDO PROBLEMAS}

Para que alguém se perceba como capaz de resolver problemas é necessário, antes de tudo, saber reconhecer o que é um problema (Davidson, Deuser, Sternberg, 1994). Para que isto ocorra, é preciso que haja a necessidade de atingir um objetivo, sem que se saiba de antemão como proceder para alcançá-lo. Pozzo parte da formulação clássica de Lester, que define problema como "uma situação que um indivíduo ou um grupo quer ou precisa resolver e para a qual não dispõe de um caminho rápido e direto que o leve à solução", para depois completá-la: "um problema é, de certa forma, uma situação nova ou diferente do que já foi aprendido, que requer a utilização estratégica de técnicas já conhecidas"( 1998, p. I5). Essas características explicitam a diferença entre um problema e um exercício. $\bigcirc$ exercício apresenta-se como uma situação em que existe um objetivo a ser atingido, mas diante da qual se conta com procedimentos conhecidos capazes de conduzir diretamente à solução. Sua função é treinar e consolidar habilidades e técnicas básicas, que só terão utilidade no auxílio da resolução de nova situação, se estiverem dominadas o suficiente para que possam ser reconhecidas, adequadas ou transferidas para outros contextos.

Essa é a razão pela qual uma determinada situação pode representar um problema para uma pessoa e um simples exercício, ou mesmo não existir, para outra. Encontrar caminhos de resolução depende tanto da disposição como do conhecimento prévio do sujeito, reside na interação da experiência pessoal com a demanda da tarefa, ou seja, do interesse que desperta em cada um, dos mecanismos que cada um possui para desvendá-la, dos conhecimentos conceituais e dos recursos cognitivos atuantes. Essa concepção de problema, como veremos mais adiante, implica que o sujeito corra alguns riscos, valendo-se de estratégias cognitivas associadas ao conteúdo em questão.

Resolver problemas requer o uso de estratégias, reflexões e tomada de decisão, a respeito dos passos a serem seguidos, que não são solicitadas pelos exercícios. Envolve raciocinar percorrendo diferentes etapas, as quais vão desde a identificação do problema, de sua natureza e da melhor forma de representálo mentalmente, passando pela construção de estratégias, pela organização das informações disponíveis e pela alocação dos recursos necessários e do tempo disponível, até o monitoramento desse processo e a avaliação dos resultados conseguidos (Sternberg, 2000). Como pode ser percebido, as tarefas de re- 
solução de problemas exigem reflexão sobre como se está pensando e sobre o que se está pensando. Só assim parece ser possível promover um domínio mais consciente dessas habilidades, resultando em seu emprego de maneira mais planejada e controlada, bem como na possibilidade de generalizá-las para outras situações de aprendizagem (Bruner, 200l).

As etapas que compõem a resolução de problemas não atuam como receita para se obter sucesso nessa tarefa. Para atingir esse fim, é preciso que o sujeito construa um pensamento flexível: perceba novas relações, descarte elementos que a princípio pareciam relevantes, mude sua representação mental do problema e, especialmente, empregue heurísticos como orientadores de procedimentos iniciais e gerais da resolução de problemas. $\bigcirc$ pensamento flexível é, portanto, fundamental na organização e resolução de uma situação que, num primeiro momento, parece insolúvel, gerando ainda e, em especial, confiança no próprio pensar.

\section{IMAGINANDO SOLUÇÕES: OS HEURÍSTICOS}

Polya, escrevendo na década de 40 sobre solução de problemas, mostra que tarefas dessa natureza implicam a percepção de autocompetência. Para ele, a satisfação da descoberta atua como incentivo para que o sujeito se arrisque a desvendar novos problemas (Polya, 1995). De igual modo, Bruner (1973) aposta no fascínio de "imaginar uma solução" e acredita que a desafiante tarefa de solucionar problemas, vinculada sem dúvida à observação e ao raciocínio, guarda espaço nobre para uma "pitada" essencial de adivinhação. E, por trás da arte da adivinhação, atuam os heurísticos.

De acordo com Schoenfeld (1980), heurístico é uma estratégia ou sugestão geral, independente de qualquer tema ou disciplina em particular, que auxilia o sujeito a aproximar-se do problema, a compreendê-lo e a guiar, de maneira potencialmente eficaz, seus recursos para resolvê-lo. Tal como se entende, os procedimentos heurísticos são vagos, intuitivos e especulativos. Não oferecem garantia de sucesso, mas constituem a melhor forma de analisar e selecionar as variáveis relevantes de uma situação desconhecida. Resolver problemas, em virtude de sua própria natureza, envolve erro e incerteza. A possibilidade de fracasso e de fazer escolhas que em muito se distanciam das que levariam ao sucesso fazem parte desse processo. Os heurísticos implicam esse risco mas, ainda assim, recorrer a eles é a melhor maneira de sair do 
Metacognição e sucesso escolar...

imobilismo. Desse modo, ao empregar heurísticos, aprende-se também a aceitar erros e a conviver com um estado de incerteza temporário, situações desconfortáveis em razão de contrariar as expectativas acerca do que vem a ser ensinar e aprender, mas necessárias para enfrentar as tarefas escolares e as situações de vida cotidiana.

Os heurísticos diferenciam-se, assim, dos algoritmos, que são procedimentos diretos, já bem conhecidos pelo sujeito e, por isso, praticamente automatizados. Um algoritmo pode ser entendido como um conjunto predeterminado e bem definido de regras e processos destinados à solução de um grupo de problemas semelhantes, com um número finito de etapas'. Trata-se, portanto, de um procedimento que implica conhecimentos já adquiridos que permitem transformar a informação de maneira padronizada e eficaz, atingindo, sempre que utilizado de maneira pertinente, seu objetivo. Infelizmente, grande parte das situações que se apresentam na escola e fora dela não podem ser solucionadas por meio da aplicação de algoritmos. Daí a importância da cultura escolar proporcionar à sua clientela muitas e diversificadas situações que requeiram o emprego de heurísticos. De maneira geral, os seguintes heurísticos são os mais freqüentemente utilizados (Nunes, Davis, Setúbal, 200I):

- Tentativa e erro: escolha totalmente aleatória e cega, bastante primitiva, custosa e, quando efetiva, não esclarece ao sujeito nem sobre sua forma de pensar nem sobre a estrutura da tarefa, de modo que se torna impossível avaliar o resultado encontrado e, conseqüentemente, aprender e transferir conhecimento.

- Aproximações sucessivas: a resolução inicia-se de forma aleatória ou estimada mas, por meio da análise dos resultados alcançados, faz-se uma ou mais tentativas que se aproximam, paulatinamente, do resultado esperado, até se chegar a ele.

- Análise da relação meio/fins : identificação da estrutura da tarefa e comparação constante entre o estado atual e o estado final, considerando as etapas e procedimentos pertinentes para minimizar as diferenças entre os dois estados.

I. Dicionário Aurélio Eletrônico (1996). Sternberg (2000) também cunha sua definição para algoritmo: "caminho formal para alcançar uma solução, que envolve um ou mais processos repetitivos, os quais, geralmente, levam a uma resposta exata da questão" (p.337). 
- Decomposição do problema: o objetivo final do problema é quebrado em submetas, cada uma delas sendo tratada como se fosse um problema por si só. A partir daí dois procedimentos são possíveis:

a. operação "do fim para o início": o objetivo final é identificado e, a partir dele, por meio de análise, estabelece-se o passo imediatamente anterior a ele e assim sucessivamente, até que o estágio inicial do problema seja identificado e este possa, então, ser resolvido;

b. operação "do início para o fim": parte dos dados do problema e identifica o passo imediatamente seguinte, resolvendo-o; com base nesses resultados, identifica-se a próxima etapa e assim sucessivamente.

- Procura de problema análogo: os procedimentos já conhecidos são examinados e, dentre eles, identifica-se aquele que mais se aproxima do problema proposto, na medida em que fornece indicadores que podem nortear a busca de soluções.

- Descrição e/ou representação do problema de maneira explíita, tornando-o um documento "público": as características centrais do problema devem ser listadas, esquematizadas, organizadas em gráficos ou tabelas, permitindo uma representação mais complexa das relações realizadas mentalmente, forçando, de um lado, o sujeito a explicitar como pretende alcançar os resultados esperados e perceber com mais clareza os obstáculos a serem enfrentados; de outro, permite tornar o pensamento público, possibilitando que outras pessoas se envolvam na resolução da tarefa, seja para orientá-la, seja para dela compartilhar.

- Aprimoramento da solução: as soluções encontradas precisam e devem ser mais bem elaboradas de modo a tornar os resultados mais elegantes, precisos, concisos e/ou objetivos, incorporando novas idéias ou soluções mais sofisticadas, e/ou eliminando noções nebulosas, confusas ou pouco práticas.

O ensino formal, tal como costuma acontecer nas escolas, abre pouco espaço para se trabalhar explicitamente com questões relativas ao pensamento, especificando os tipos de heurísticos, quando usá-los e por que ora um ora outro se mostra mais eficaz. No entanto, conforme já mencionado, é possível 
Metacognição e sucesso escolar...

fazer diferente, abrindo um espaço para tratar desses assuntos de maneira criativa, levando em conta o cotidiano dos alunos, seus conhecimentos prévios, seus interesses, bem como as necessidades curriculares. Descreveremos a seguir um projeto que segue nessa direção, discutindo algumas situações em que a cultura do pensamento vigora na sala de aula.

\section{HEURECA! TEM GENTE ENSINANDO A PENSAR!}

○ Laboratório Didático Virtual - LabVirt (Nunes, 2002) volta-se, sobretudo, para o ensino de Física no ensino médio. Nesse projeto, os alunos de escolas públicas, durante o período normal de aulas e dentro dos assuntos curriculares, são convidados a propor situações-problema nas quais os tópicos da Física, que serão abordados durante o curso, podem ser utilizados, servindo como situação de aprendizagem para outros alunos. As propostas dos estudantes são usadas como mote para a aquisição dos conhecimentos teóricos necessários. Os professores elegem um assunto como importante e abrem espaço e oportunidade para que os alunos manifestem suas concepções sobre ele: o que já conhecem a respeito, como avaliam sua importância, como acreditam ser utilizado no cotidiano, quais supõem serem os mecanismos básicos de seu funcionamento etc. A aprendizagem, quando parte do que os alunos sabem, promove um envolvimento maior. Com isso, muitos daqueles anteriormente desinteressados passam a participar ativamente das atividades da sala de aula.

Os problemas criados pelos alunos devem ser formulados no formato de um roteiro que, fazendo uso dos conceitos da Física, norteará a elaboração de uma situação-problema, a ser programada em forma de simulação para uso em computador. Essa atividade requer, de fato, a construção de situações que envolvam a compreensão dos conceitos da física e seu emprego, bem como o planejamento da ação (desde a elaboração de estratégias de pensamentos até o monitoramento do próprio processo de resolução da tarefa). Além disso, a concepção e a "encomenda" de uma situação-problema de Física é, por si só, tarefa nova, aberta e desafiadora, pois gera um produto final, uma "simulação", na qual o usuário pode introduzir eventuais modificações nos parâmetros necessários à sua resolução.

A encomenda de uma situação problema mostra-se bastante motivadora para os alunos, sobretudo porque eles sabem de antemão que sua produção será programada em computador, na forma de uma simulação digital com 
animação, cor, som e interatividade, a ser colocada na web à disposição de outros alunos e professores de sua e de outras escolas. Cabe esclarecer que não é necessário que os alunos dominem programação ou design gráfico, nem que tenham muitas habilidades com computadores. A abordagem do projeto prevê uma interface com a universidade ${ }^{2}$ na qual alunos de graduação ou pós-graduação em Artes, Computação, Arquitetura, Engenharia e Física participam da elaboração das simulações a título de estágios de seus cursos. Suporte na forma de apoio ao planejamento e desenvolvimento das aulas é garantido aos professores das escolas públicas por pesquisadores da universidade.

Em termos de avaliação, dois instrumentos - ata e rubrica - foram construídos ao longo do projeto, de modo a auxiliar o professor a acompanhar o trabalho dos alunos em um projeto novo, que ainda não Ihe era familiar. A ata tem a finalidade de fazer com que professores e alunos acompanhem o funcionamento do grupo, bem como de cada um de seus participantes. Nela, toda participação e manifestação dos estudantes é registrada. A elaboração da ata, juntamente com o desenvolvimento do trabalho em equipe, obedece a uma definição de papéis que se alternam a cada aula (anotador, mediador, cronometrista etc.). Esse instrumento cumpre um papel informativo para o grupo, estimulando seus membros a ficarem atentos ao processo de trabalho.

Já a rubrica auxilia na definição de critérios objetivos de avaliação, os quais são anunciados para os alunos. Em um trabalho do tipo "criação de situaçãoproblema e encomenda de simulação", é elevado o número de dimensões de aprendizagem (Mansilla e Gardner, 1997) envolvidas, e complexa a forma como elas se relacionam com as habilidades e competências. A dificuldade de contemplar essa diversidade na avaliação levou à elaboração de uma rubrica instrucional ${ }^{3}$ (Andrade, 2000) personalizada para facilitar o trabalho. Nem todas as dimensões são trabalhadas simultaneamente no desenvolvimento das situações-problema. As dimensões de aprendizagem, tal como apresentadas por Mansilla e Gardner (1997), são:

2. O projeto Laboratório Didático Virtual é desenvolvido na Escola do Futuro da USP-SP e conta com a participação de diversos institutos dessa universidade.

3. O nome "rubrica instrucional" vem de uma linha de pesquisadores da Faculdade da Educação de Harvard que usa esse tipo de instrumento tanto para avaliar como para indicar ao aluno caminhos que ele deve seguir para atingir os objetivos propostos para a atividade. 
Metacognição e sucesso escolar...

- Dimensão do conhecimento, que contempla as transformações dos conceitos espontâneos e a formação de uma rede conceitual rica e coerente.

- Dimensão dos métodos, na qual se desenvolve um ceticismo saudável, passando-se a trabalhar nas modalidades de construção do conhecimento peculiares a diferentes disciplinas e nas maneiras de validação desse conhecimento.

- Dimensão dos objetivos ou propósitos, na qual os alunos se tornam conscientes da aplicabilidade e objetivo do conhecimento em determinada área, desenvolvendo sua autonomia.

- Dimensão das formas, responsável pela apropriação de diversas modalidades de apresentação e expressão próprias de uma determinada área, considerando tanto sua simbologia e linguagem como o contexto e a audiência para a qual se dirige.

processo de elaboração da rubrica é bastante rico. Vale aqui destacar, por exemplo, que um professor, após alguns minutos trabalhando na elaboração desse instrumento, comentou em tom indignado: "se dermos todos esses detalhes para os alunos, logicamente todos vão bem". Mas, antes mesmo de terminar a frase seu tom já tinha mudado, indicando que se apercebera do potencial do instrumento. Assim, completou: "É, mas é isso que queremos!". Apresentamos, a seguir, a rubrica utilizada por um dos professores participantes do projeto, que elucida seus critérios de avaliação, bem como sua gradação de acordo com o assunto a ser trabalhado.

$\bigcirc$ uso dessa rubrica, no projeto, mostrou-se variado: alguns professores a utilizam apenas como instrumento pessoal de avaliação; outros solicitam que cada aluno a empregue em situações de auto-avaliação. Em algumas classes, a rubrica é utilizada em todas as aulas e, em outras, apenas no momento em que as encomendas ficam prontas. Esse instrumento foi fundamental para assegurar aos professores como seria o processo, sua participação e a dos alunos, permitindo-Ihes trabalhar com segurança com várias classes simultaneamente.

Esse projeto ilustra bem o que se entende por cultura do pensar, sendo possível, ainda que indiretamente, considerar como a metacognição pode auxiliar na aprendizagem. Vejamos como isso ocorre, discutindo a seqüência didática de um professor que trabalhou o tema "queda livre" com seus alunos. 
RUBRICA: QUEDA-LIVRE

\begin{tabular}{|c|c|c|c|c|c|}
\hline Critérios & 4 & 3 & 2 & I & Pontuação \\
\hline $\begin{array}{l}\text { Domínio dos } \\
\text { conceitos e } \\
\text { procedimentos } \\
\text { da Física }\end{array}$ & $\begin{array}{c}\text { Conhece os } \\
\text { conceitos de } \\
\text { queda-livre, } \\
\text { aplica-os em } \\
\text { situações simples } \\
\text { ou reais e mais } \\
\text { complexas }\end{array}$ & \begin{tabular}{|c|} 
Conhece os \\
conceitos de \\
queda-livre, mas \\
só sabe aplicar \\
em situações \\
simples \\
propostas
\end{tabular} & $\begin{array}{l}\text { Conhece os } \\
\text { conceitos de } \\
\text { queda-livre, } \\
\text { mas não sabe } \\
\text { aplicá-los }\end{array}$ & $\begin{array}{l}\text { Não sabe } \\
\text { aplicar as } \\
\text { funções do } \\
\text { MRUV* na } \\
\text { queda-livre }\end{array}$ & \\
\hline $\begin{array}{l}\text { Originalidade } \\
\text { da situação- } \\
\text { problema } \\
\text { formulada }\end{array}$ & $\begin{array}{c}\text { A idéia e a } \\
\text { encomenda } \\
\text { são inovadoras } \\
\text { e originais }\end{array}$ & $\begin{array}{c}\text { O trabalho (idéia) } \\
\text { é uma modificação } \\
\text { de algo existente } \\
\text { e a encomenda } \\
\text { é autêntica }\end{array}$ & $\begin{array}{c}\text { A idéia é } \\
\text { cópia, } \\
\text { mas a } \\
\text { encomenda } \\
\text { é original }\end{array}$ & $\begin{array}{l}\text { O trabalho } \\
\text { é cópia total }\end{array}$ & \\
\hline $\begin{array}{l}\text { Relaciona- } \\
\text { mento } \\
\text { social }\end{array}$ & $\begin{array}{c}\text { Contribui, } \\
\text { compartilha muito } \\
\text { com o grupo: } \\
\text { motiva e esforça- } \\
\text { se para manter o } \\
\text { grupo coeso } \\
\text { e incluir colegas } \\
\text { com dificuldades } \\
\text { de comunicação } \\
\text { e conteúdo }\end{array}$ & $\begin{array}{l}\text { Contribui e } \\
\text { compartilha } \\
\text { razoavelmente } \\
\text { com o grupo }\end{array}$ & $\begin{array}{c}\text { Contribui ou } \\
\text { compartilha } \\
\text { apenas } \\
\text { superficialmente } \\
\text { com o grupo }\end{array}$ & $\begin{array}{c}\text { Não contribui } \\
\text { com o grupo } \\
\text { por não fazer } \\
\text { nada ou por } \\
\text { não querer } \\
\text { compartilhar seus } \\
\text { conhecimentos }\end{array}$ & \\
\hline Pontualidade & $\begin{array}{c}\text { Sempre entrega } \\
\text { as tarefas } \\
\text { pontualmente }\end{array}$ & $\begin{array}{c}\text { Quase sempre } \\
\text { entrega as tarefas } \\
\text { no prazo }\end{array}$ & $\begin{array}{c}\text { Quase sempre } \\
\text { entrega as tarefas } \\
\text { com atraso }\end{array}$ & $\begin{array}{c}\text { Não entrega } \\
\text { as tarefas }\end{array}$ & \\
\hline $\begin{array}{l}\text { Capacidade } \\
\text { de expressão }\end{array}$ & $\begin{array}{c}\text { É convincente } \\
\text { e se expressa } \\
\text { com facilidade, } \\
\text { utilizando os } \\
\text { conceitos da } \\
\text { Física }\end{array}$ & $\begin{array}{c}\text { Expressa-se } \\
\text { satisfatoriamente }\end{array}$ & $\begin{array}{c}\text { Não se expressa } \\
\text { claramente: } \\
\text { é confuso }\end{array}$ & $\begin{array}{c}\text { Não articula } \\
\text { nem expressa } \\
\text { suas idéias }\end{array}$ & \\
\hline
\end{tabular}

*MRUV: Movimento retilíneo uniformemente variável. 
Metacognição e sucesso escolar...

\section{$\checkmark I^{\text {a }}$ aula: Propondo a tarefa}

professor começa com a apresentação da proposta de trabalho e de avaliação. Em relação à primeira, esclarece que seu objetivo é planejar uma situação-problema por meio da qual se possa entender a noção de queda-livre. Quanto à segunda, aponta o uso da rubrica, discute os critérios com os alunos, e anuncia que cada grupo deve redigir uma ata, conforme mencionado, relatando cada uma de suas reuniões. Inicia com a classe uma discussão sobre quedalivre, utilizando como mote a queda de vasos de diferentes tamanhos que caem de diferentes janelas. Levanta, a partir de comentários dos alunos, os conceitos físicos envolvidos: velocidade, tempo de queda, altura, massa etc. Em seguida, com a classe já ciente de que seu trabalho será transformado em simulações para computador, convida-a a pensar em situações semelhantes, que possam despertar a curiosidade sobre o tema. Ao final da primeira aula, os alunos se auto-avaliam utilizando a rubrica, procedimento que se repetirá em todas as demais. De igual modo, cada aula é registrada em ata, identificando-se as atividades realizadas, seus principais atores, as principais dúvidas e descobertas etc.

\section{$\checkmark 2^{\mathrm{a}}$ aula: Motivando e oferecendo modelo}

Como muitos alunos não têm idéia de como pode ser uma simulação de uma situação-problema, vão ao laboratório de informática e acessam uma simulação de dois trapezistas que não conseguem sincronizar seus movimentos, de modo que um deles cai. A abertura dessa simulação é feita com uma linguagem lúdica - um dos trapezistas, o que despenca, é franzino e treme de medo antes de se lançar da plataforma. Esse tipo de cena cumpre o papel de apontar aos alunos que eles podem, perfeitamente, imaginar situações e roteiros, criando um contexto atraente para ensinar conceitos de física. Como exemplo, mostramos duas telas dessa simulação, tal como idealizada por uma professora:

uso de simulações para motivar, introduzir assuntos, visualizar efeitos complicados e, inclusive, desafiar concepções espontâneas é o núcleo central dos trabalhos desenvolvidos no LabVirt. Deve-se ressaltar que a escolha de uma simulação que sirva de motivação e modelo para os alunos deve ser cuidadosa, na medida em que se evita, a todo custo, induzir pensamentos e inibir a criatividade. A partir desse modelo de simulação, os alunos estão em condições, ainda que nem sempre tenham consciência disso, de representar men- 
talmente um problema de queda-livre. Começam, então, a esboçar seus próprios roteiros para as simulações.

TELAS I E 2

\section{ILUSTRANDO AS SIMULAÇÕES}
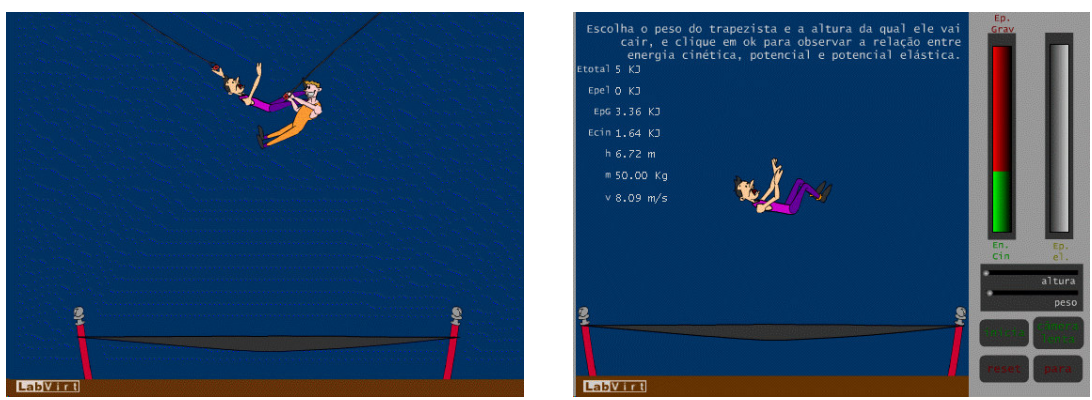

Acessada em: http://www.labvirt.futuro.usp.br/simulacoes/fisica/sim_energia_trapezista.htm

A leitura das atas aponta que, nesse processo, apareceram muitas concepções espontâneas dos alunos sobre a queda-livre. A mais comum foi a de que objetos de massas diferentes caem com velocidades diferentes. A simulação dos trapezistas permitiu que os alunos percebessem que essa concepção não era adequada. Na classe em questão, os estudantes consideraram importante, dada a freqüência com que essa noção equivocada apareceu na sala de aula, criar situações que levassem o usuário a construir a idéia correta. Isso quer dizer que perceberam qual era sua apreensão do fenômeno, notaram que ela era improcedente, entenderam que muitas outras pessoas compartilhavam dessa concepção (ou seja, que ela era de senso comum) e criaram uma situação para ensinar o conceito científico ao usuário.

\section{$\checkmark 3^{\mathrm{a}}$ aula: Explicando com vocabulário preciso}

Em razão da fragilidade do conceito espontâneo de queda-livre, o professor explica o conceito científico, relacionando-o à teoria de movimento uniformemente acelerado. Pede, então, a resolução de uma lista de exercícios de modo a propiciar a consolidação das noções aprendidas. Em seguida, reto- 
Metacognição e sucesso escolar...

ma o processo de elaboração das encomendas, solicitando aos estudantes que criem um enunciado para o problema que estão propondo, com utilização de vocabulário específico da Física. Percebe-se, aí, a presença de outros recursos necessários para se construir uma cultura do pensamento: a explicação clara e o vocabulário preciso e partilhado por todos da classe.

\section{$\checkmark 4^{\text {a }}$ aula: Recorrendo a estratégias de pensamento}

$\bigcirc$ professor solicita aos alunos que enunciem e resolvam as situaçõesproblema que criaram, fixando valores pertinentes para as variáveis-chave. Após resolverem essa tarefa, o professor comenta que a simulação, para ser interativa, interessante e promotora da aprendizagem, deve possibilitar que o usuário teste suas próprias hipóteses. Aponta, assim, a necessidade de uma solução genérica do problema, válida para qualquer valor escolhido. Essa solução genérica é a chamada solução algébrica, algo que constitui um novo e maior desafio para os alunos, os quais precisam investir tempo e esforços para desenvolver estratégias de pensamento capazes de solucionar o problema. Essa é, como pode ser visto, uma situação didática que favorece o emprego de heurísticos, em especial de tipo análise meio/fins, a busca de problemas análogos, aproximação sucessiva e outros.

\section{$\checkmark 5^{\mathrm{a}}$ aula: Aprendendo com o erro}

Percebendo que o trabalho de resolução de problemas não é simples, o professor dedica toda a aula para discutir a solução encontrada em cada grupo. Nessa ocasião, os alunos têm oportunidade de pensar, resolver e discutir as soluções genéricas encontradas. $\bigcirc$ professor acompanha o trabalho dos diferentes grupos, esclarecendo dúvidas, mostrando as implicações de se seguir um determinado raciocínio, demandando as evidências que dão apoio às conclusões, ajudando, enfim, os estudantes a vencer suas dificuldades e a aprender com os erros cometidos.

\section{$\checkmark 6^{\mathrm{a}}$ aula: Caminhando do nebuloso ao nítido}

Os alunos começam a transformar suas idéias, esboços, enunciados e resolução dos problemas em encomendas de simulação, algo que requer, no- 
vamente, identificação das variáveis críticas, planejamento das diferentes etapas, monitoramento de seu processo de implementação e avaliação do resultado final. Após terem concluído essa fase, realizam uma avaliação do trabalho de seus pares: cada grupo analisa a encomenda de outro grupo, fazendo uso da mesma rubrica adotada para a auto-avaliação. Nesse processo, apontam como as propostas de encomenda de simulações podem ser aprimoradas (indicando dados que faltam, percebendo falhas entre as etapas, sugerindo melhorias na linguagem etc.). A experiência tem mostrado que os alunos são bastante críticos, fornecendo comentários pertinentes que economizam tempo do professor em correção e revisão. Em mais uma aula, os alunos terminam suas encomendas e as enviam à universidade pelo site do LabVirt.

\section{$\checkmark 7^{\mathrm{a}}$ aula: Construindo uma auto-imagem de aprendiz competente}

Quando as simulações ficam prontas, em geral duas semanas após o envio da encomenda, a aula consiste em "ver e comentar" coletivamente as simulações já acessíveis via internet. Os pontos importantes dessa avaliação consistem em propiciar ocasião de interação e o feedback de alunos e professores a respeito do produto final de seu trabalho. Perceber que a proposta foi compreendida por outros que a transformaram em animações passíveis de promover novas aprendizagens em novos alunos parece ser uma experiência extremamente gratificante. Conclui-se o trabalho, portanto, com os alunos sentindo que são aprendizes competentes, algo que lhes incita a enfrentar novos e maiores desafios.

\section{IRADO! TEM GENTE APRENDENDO A PENSAR!}

Como pode ser visto, essa seqüência didática permite espaço para que idéias e exemplos dos alunos sejam trabalhados, possibilitando o uso da criatividade e, em especial, motivando a classe para conhecer mais a respeito da teoria. Mais importante ainda, essa prática pedagógica tem o mérito de permitir identificar os andaimes necessários para que os alunos ultrapassem as barreiras que se colocam à criação e resolução de problemas abertos, valorizando o aprender na medida em que promove o orgulho do que se foi capaz de produzir.

No que concerne ao uso da rubrica, fica claro que ela permite conhecer com precisão os critérios por meio dos quais os alunos serão avaliados, e 
Metacognição e sucesso escolar...

que se está solicitando deles uma participação diferente daquela a que estão acostumados. É curioso notar que os estudantes, diferentemente do que se poderia supor, não se dão nota máxima, preocupando-se, antes, em aprimorar os aspectos que consideraram mais frágeis. Percebe-se que aos poucos se tornam mais críticos e capazes de notar os problemas que eventualmente aparecem nas diferentes encomendas. Comentários do tipo: "quem for produzir não vai entender o que vocês querem, se vocês não disserem o que deve aparecer na tela e deixar claro como a simulação deve funcionar". Dessa maneira, o fato de a mesma rubrica ser empregada pelo professor para avaliar cada aluno, e destes a utilizarem tanto para se auto-avaliar como para avaliar os colegas, propicia não apenas a apropriação de uma visão crítica como também a transparência de todo o processo avaliativo.

Um exemplo de situação-problema, elaborada por estudantes do $1^{\circ}$ ano do ensino médio, no início, portanto, do curso de Física, é apresentado a seguir. Ele ilustra como os alunos foram capazes de, com um pouco de Física que aprenderam, encontrar um problema real no qual praticamente todos os conceitos que conheciam até o momento foram aproveitados. Adicionalmente, indica a apreensão de que o heurístico "decomposição do problema do fim para o início" é necessário para que ele tenha números e solução realistas. Trata-se de uma corrida de stockcar, na qual um veículo está mais leve e veloz do que outro por ter partido com o tanque de gasolina mais vazio. Esse fato, no entanto, implica a necessidade de uma parada para abastecimento. A questão para o usuário é encontrar o tempo máximo que o carro pode parar no box para abastecer, sem que perca a corrida

A tela seguinte mostra como a escolha de dados precisou ser cuidadosa, para que os valores de velocidade, distância e tempo fossem adequados para simular, com base na realidade, o problema. Os alunos conseguem representar a essência do problema: o tamanho da pista (de 20 km) é razoável para uma corrida. As velocidades médias dos carros (de 170 e 180 km/h) também são valores plausíveis. $\bigcirc$ tempo de parada no box - considerando desaceleração, abastecimento e aceleração, de 23seg. - é, novamente, realista. O problema foi criado, portanto, de maneira que a resposta e os dados utilizados pudessem ser considerados parâmetros reais. Adicionalmente, as aproximações feitas (trabalho com velocidades e tempos médios) não comprometem a representação. Ao contrário, elas permitem que os alunos empreguem todo o conhecimento de física que adquiriram até aquele momento. 
TELA 3

ILUSTRAÇÃO DO CONHECIMENTO ATUAL DOS ALUNOS, POR MEIO DA SIMULAÇÃO FEITA

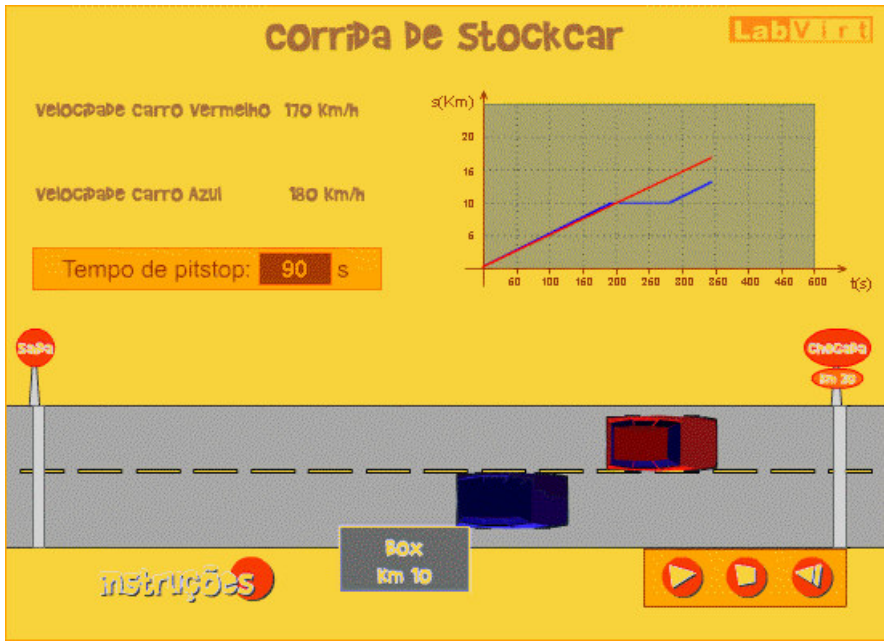

Os alunos preocuparam-se, ainda, em fornecer feedback ao usuário em caso de erro:

TELA 4

ILUSTRAÇÃO DE FEEDBACK FEITA PELOS ALUNOS

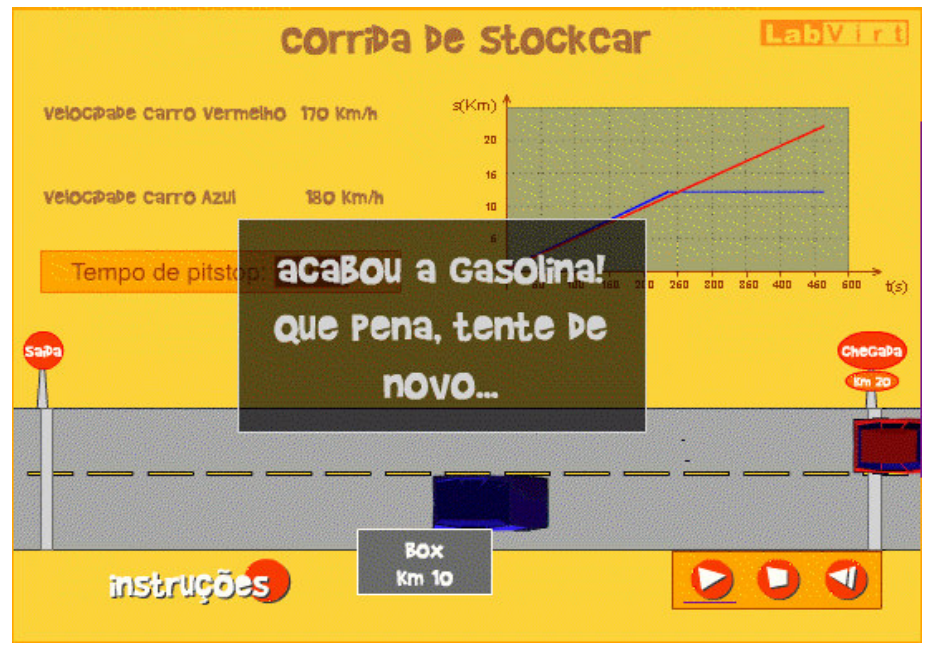


Metacognição e sucesso escolar...

método de trabalho do projeto LabVirt, atualmente em expansão para as áreas de Biologia, Matemática e Química, permite que os alunos trabalhem com problemas legítimos, motivadores e desafiantes para eles mesmos. Os procedimentos utilizados, bem como as rubricas de avaliação e o planejamento aula a aula, permitem o acompanhamento do processo de criação do problema e problematização em termos dos conceitos da Física, considerando a audiência. A criatividade dos alunos não é, em momento algum, tolhida. Ao contrário, é incentivada explicitamente por instrumentos de avaliação e divulgação do produto final. Os problemas criados e resolvidos tendem a não ser estruturados, permitindo múltiplos caminhos e abordagens, o que evita a "automatização" da resposta. Há uma ênfase na representação gráfica dos problemas pelo fato de eles serem apresentados como simulações. Contudo, como a especificação da encomenda precisa encampar os conceitos da Física, outros heurísticos são necessariamente envolvidos. Os alunos precisam, ainda, gerenciar os recursos disponíveis - tempo, conhecimentos e interlocutores - ou seja, recorrer à atividade metacognitiva. Como conseqüência desse tipo de trabaIho, os alunos vão sendo gradativamente inseridos na cultura do pensamento. Aprendem, assim, conteúdos e formas de pensar, colocando-as a serviço do outro, desenvolvendo a cooperação. Pouco a pouco, tornam-se cada vez mais conscientes de seu próprio processo de trabalho e de sua maneira de aprender. Em outras palavras, desenvolvem a metacognição.

\section{UM OLHAR METACOGNITIVO SOBRE A APRENDIZAGEM}

Ao final deste artigo, podemos dizer que é hoje amplamente reconhecido (Organização para Cooperação e Desenvolvimento Econômico - OCDE, 200 I) que, a despeito do empenho de inúmeros alunos em aprender não ser bem-sucedido, esse fracasso não pode ser atribuído a problemas cognitivos e, sim, a dificuldades metacognitivas. Aqueles que não se saem bem na escola dispõem, como bem sabemos, de diversos conhecimentos e competências. A raiz do problema parece residir, portanto, menos na falta de saberes e habilidades do que no fato de não conseguirem nem utilizá-los, nem transferi-los para outras situações. Wong ( 1985 ) afirma que os desastres da aprendizagem decorrem do fato de os alunos "não saberem o que sabem" e, como bem indica Flavell ( 1985), a consciência do que se sabe - e do que não se sabe - pertence ao reino dos conhecimentos metacognitivos. Crianças e adolescentes em 
situação de fracasso enfrentam dificuldades até mesmo para acionar os processos de controle capazes de guiar sua atividade, com autonomia, na direção do fim almejado. Faltam-Ihes métodos de trabalho, motivação e, conseqüentemente, persistência nas tarefas.

Essa situação é mais grave do que aparentemente se supõe: na medida em que os alunos não conseguem ser sujeitos de sua própria aprendizagem, eles também não o serão em face da cultura a ser conquistada por intermédio de tais aprendizagens. Desse modo, é tarefa central empenhar-se para propiciar, desde sempre, o esforço cognitivo e o desenvolvimento das habilidades metacognitivas, para se alcançar a independência intelectual imprescindível ao exercício da cidadania. Tais competências, justamente por serem úteis nas aprendizagens escolares, levam Flavell a propor que devem fazer parte integrante do currículo escolar. Ensinando-as, é possível construir na escola uma cultura do pensar que, aliando conteúdos, raciocínios e valores, permitirá a formação de pessoas aptas a tomarem decisões acertadas, por terem aprendido que não é suficiente apenas saber e/ou fazer: a chave está em saber como se faz para saber e como se sabe para fazer.

\section{REFERÊNCIAS BIBLIOGRÁFICAS}

ANDRADE, H. G. Using rubrics to promote thinking and learning. Educational Leadership, V.57, n.5, p.13-18, 2000.

AUSUBEL, D. P.; NOVAK, J. D.; HANESIAN, H. Psicologia Educacional. 2.ed. Rio de Janeiro: Interamericana, 1980.

BRUNER, J. Beyond the information given: studies in the psychology of knowing. New York: Norton, 1973.

A Cultura da educação. Porto Alegre: Artmed, 2001.

CLARKE, J. H. Patterns of thinking : integrating learning skills in content teaching. Massachusetts: Allyn and Bacon, 1990.

DAVIDSON, J. E.; DEUSER, R.; STERNBERG, R. J. The role of metacognition in problem solving. In: MET CALPE, J.; SHIMAMURA, A. P. Knowing about Knowing. Cambridge, Ma: MIT, 1994. p.207-226.

DOLY, A. M. Metacognição e mediação na escola. In: GRANGEAT, M. (coord.) A Metacognição: um apoio ao trabalho dos alunos. Porto: Porto Editora, 1999. 
Metacognição e sucesso escolar...

FLAVELL, J. H. Cognitive development. New Jersey: Prentice Hall; Englewood Cliffs, 1985. Metacognitive aspects of problem solving. In: RESNIK, L. B. (ed.) The Nature of intelligence. Hillsdale, NJ: Lawrence Erlbaum, 1976. p.23 I-236.

GOODRICH, H. W. Student self-assessment: at the intersection of metacognition and authentic assessment. Cambridge, Ma, 1996. (Ph. D.) thesis. Graduate School of Education, Harvard University.

GRANGEAT, M. A Metacognição: um desafio a autonomização. In: GRANGEAT, M. (coord.) A Metacognição: um apoio ao trabalho dos alunos. Porto: Porto Editora, 1999.

GRANGEAT, M. (coord.). A metacognição: um apoio ao trabalho dos alunos. Porto: Porto Editora, 1999.

MANSILLA, V. B.; GARDNER, H. What are the qualities of understanding? In: WISKE, M. S. Teaching for understanding : linking research with practice. San Francisco: Jossey-Bass, 1997.

NUNES, C. A. A. Collaborative content creation by cross-level students. [Apresentado no $2^{\text {th }}$ International Conference on Open Collaborative Design for Sustainable Innovation: creativity, control and culture for sustainable change. Bangalore, India, I -2 Dec. 2002.] (Disponível em http://thinkcycle.media.mit.edu/thinkcycle/main/development_by_design_2002/ publication_collaborative_content_creation_by_cross_level_students/.

NUNES, C. A. A.; DAVIS, C.; SETÚBAL, M. A. Novas tecnologias, novas formas de aprender? Brasília: CNPq, 200 I. [Relatório técnico]

ORGANIZAÇÃO PARA A COOPERAÇÃO E DESENVOLVIMENTO ECONÔMICO (OCDE). Conhecimentos e atitudes para a vida: resultados do Pisa 2000. São Paulo: Moderna, 2001 .

POLYA, G. A Arte de resolver problemas. Rio de Janeiro: Interciências, 1995.

POZZO, J. I. (org.) A Solução de problemas: aprender a resolver, resolver para aprender. Porto Alegre: Artmed, 1998.

SCHOENFELD, A. H. Heuristics in the classroom. In: KRULIK, S.; REYS, R. (eds.) Problem solving in school mathematics. National Council of Teachers of Mathematics, 1980. p. 19-22 (Yearbook).

. Learning to think mathematically: problem solving, metacognition and sense making in mathematics. In: GROUWS, D. A. (ed.) Handbook of mathematics teaching and learning. New York: McMillan, 1992. p. 334-370.

STERNBERG, R. J. Intelligence applied: understanding and increasing your intellectual skills. Sandiego: Harcourt Brace Jovanovich, 1986. 
Psicologia cognitiva. Porto Alegre: Artmed, 2000.

TISHMAN, S.; PERKINS, D. N.; JAY, E. A Cultura do pensamento na sala da aula. Porto Alegre: Artmed, 1999.

VYGOTSKY, L. S. A Formação social da mente. 4.ed. São Paulo: Martins Fontes, 1991. Pensamento e linguagem. São Paulo: Martins Fontes, 1987.

WONG, B. Y. L. Metacognition and learning disabilities. In: FORREST-PRESLEY, D. L.; MACKINNON, G. E.; WALLER, T. G. (eds.) Metacognition, cognition and human performance. New York: Academic Press, 1985. v.2, p. 137 - 180.

ZIMBARDO, P. G.; RUCH, F. L. Psychology and life. Palo Alto: Scott, Foresman and Company, 1977.

Recebido em: fevereiro 2005

Aprovado para publicação em: fevereiro 2005 